\title{
Anti-Glutamate Therapy in Amyotrophic Lateral Sclerosis: A Trial Using Lamotrigine
}

\author{
Andrew Eisen, Heather Stewart, Michael Schulzer and Donald Cameron
}

\begin{abstract}
Glutamate excitotoxicity is implicated in the pathogenesis of amyotrophic lateral sclerosis (ALS). We report the results of a double blind, placebo controlled, trial using $100 \mathrm{mg}$ of oral daily lamotrigine (3,5-diamino-6-(2,3 dichlorophenyl)-1,2,4-triazine) which inhibits glutamate release. 67 patients were entered and at trial termination of 1.5 years 15 had withdrawn ( 9 active and 6 placebo) and 12 had died ( 6 active and 6 placebo). Mean age at entry was 57.5 years for the active and 58.6 years for the placebo groups. Patients were seen at 3 monthly intervals and scored according to neurological deficit based upon age of onset, bulbar and respiratory involvement, ambulation and functional disability. The mean change in clinical scores for the active versus placebo groups over the trial period was $7.1 \pm 3.3$ and $9.0 \pm 3.3$ respectively $(0.05<\mathrm{p}<0.10)$. Changes in cortical threshold and MEP/CMAP ratios to magnetic stimulation also did not differ significantly between the two groups. We conclude that lamotrigine in the doses administered does not alter the course of ALS.
\end{abstract}

RÉSUMÉ: Thérapie anti-glutamate dans la sclérose latérale amyotrophique: un essai clinique avec la lamotrigine. L'excitotoxicité du glutamate est impliquée dans la pathogenèse de la sclérose latérale amyotrophique (SLA). Nous rapportons les résultats d'un essai thérapeutique à double insu, contrôlé par placebo, utilisant une dose quotidienne orale de $100 \mathrm{mg}$ de lamotrigine (3,5-diamino-6-(2,3 dichlorophényl)-1,2,4-triazine) qui inhibe la libération du glutamate. 67 patients ont été admis dans l'étude; à la fin de l'étude, soit à 1.5 ans, 15 étaient sortis de l'étude (9 patients sous médication active et 6 sous placebo) et 12 étaient décédés ( 6 sous médication active et 6 sous placebo). L'âge moyen à l'entrée dans le protocole était de 57.5 ans pour le groupe sous médication active et de 58.6 ans pour le groupe sous placebo. Les patients étaient vus aux trois mois et le déficit neurologique était évalué sur la base de l'âge de début, de l'atteinte bulbaire et respiratoire, de la marche et de l'incapacité fonctionnelle. La moyenne du changement de la cote clinique entre le début et la fin de l'étude pour le groupe sous médication active était de $7.1 \pm 3.3$ alors qu'elle était de $9.0 \pm 3.3$ pour le groupe sous placebo $(0.05<\mathrm{p}<0.10)$. De plus, les changements du seuil cortical et du rapport MEP/CMAP à la stimulation magnétique n'étaient pas significativement différents entre les deux groupes. Nous concluons que la lamotrigine, à la dose utilisée au cours de cette étude, ne modifie pas l'évolution de la SLA.

Can. J. Neurol. Sci. 1993; 20:297-30I

The pathogenesis of amyotrophic lateral sclerosis (ALS) is unknown. However, amongst other potentially relevant factors, is the role of glutamate toxicity. ${ }^{1-6}$ Glutamate is the principal fast excitatory neurotransmitter in the brain and can exert neurotoxic effects with induction of neuronal degeneration in vivo and in vitro. ${ }^{6}$ Abnormalities of glutamate metabolism may also have a role in other neurodegenerative diseases. ${ }^{1}$

Lamotrigine [3,5-diamino-6(2,3 dichlorophenyl)-1,2,4-triazine] is a phenyltriazine compound originally synthesized as one of a sequence of folic acid antagonists which has been recently licensed for use in the U.K. and Ireland as an anticonvulsant in refractory epilepsy. ${ }^{7}$ It acts mainly to inhibit excitatory aminoacid (glutamate) release and stabilizes neuronal membranes via blockade of voltage-sensitive sodium channels. It is completely absorbed after oral administration and a suggested maintenance dose for adults with epilepsy is $200-400 \mathrm{mg}$ twice daily. ${ }^{7}$
The most common side effects reported include nausea, headache, diplopia, blurred vision, dizziness and ataxia. Skin eruptions occur in about $3 \%$ of patients. There have also been a few recorded deaths in epileptics on the drug who succumbed to a rapidly progressive illness with status epilepticus, disseminated intravascular coagulation and multiorgan failure. The relationship of these deaths to lamotrigine is uncertain. ${ }^{7}$ Here we report the results of a randomized, double blind trial using lamotrigine in a dose of $100 \mathrm{mg}$ daily in patients with ALS.

\section{METHODS}

\section{Study Design}

We used a double blind placebo controlled trial. The study was designed as a survival trial with death as the end point. In addition clinical and electrophysiological data were analyzed.

From the Neuromuscular Diseases Unit, The Vancouver General Hospital and The University of British Columbia, Vancouver

Received January 11, 1993. Accepted in final form April 19, 1993

Reprint requests to: Dr. Andrew Eisen, The Neuromuscular Diseases Unit, The Vancouver General Hospital, 855 West 12th Avenue, Vancouver, British Columbia, Canada V5Z $1 \mathrm{M} 9$ 
Continuous statistical monitoring of events was carried out. We stopped the study as soon as the interim analysis showed sufficient statistical evidence for its termination. Patients were entered sequentially as they were seen in our ALS clinic and randomly assigned to receive either lamotrigine or placebo. No attempt was made in the randomization to control for a potential sex bias.

Both medications were increased up to a total oral daily dose of $100 \mathrm{mg}$ in increments of $25 \mathrm{mg}$ per week over a 4 week period. The maintenance $100 \mathrm{mg}$ tablet was administered each morning. After initial weekly and biweekly follow up, patients were reviewed every 3 months for clinical and electrophysiological assessment of disease progression. Those involved in the trial and the patients and their family members were blinded as to the medication being used.

\section{Patients}

The protocol employed was approved by the Human Ethics Committee of the University of British Columbia. Sixty-seven patients gave informed consent to participate in the trial. The criteria for entry included a diagnosis of ALS based upon the neurological history and examination and laboratory tests. ${ }^{8}$ Patients had to be ambulatory at entry and overt symptoms had to have been present for less than one year. Duration of disease was estimated from time of onset of initial symptoms to the time of trial entry. Entry criteria also included (1) a history of progressive asymmetrical muscle weakness over weeks or months, (2) clinical evidence of both upper and lower motor neuron dysfunction in the face of normal eye movements, sphincter function and sensory examination, (3) absence of significant motor or sensory conduction abnormalities and more particularly of multifocal motor conduction block checked for in at least 2 different nerves, ${ }^{9,10}(4)$ presence of electrophysiological evidence of anterior horn cell disease 11 and (5) normal imaging (CT and/or MRI) of the brain and spinal cord.

Patients with purely progressive muscular atrophy, previous poliomyelitis or post poliomyelitis syndrome, primary lateral sclerosis, monomelic amyotrophy and a family history of ALS were excluded. Also excluded were patients with severe systemic disease occurring within 2 years of developing symptoms of ALS.

\section{Clinical Evaluation}

Each patient was scored for clinical deficit at each visit. Bulbar, including respiratory difficulty was assessed independently of limb deficits. Bulbar deficit was scored 0 (= normal functioning) to 4 (= unintelligible speech and/or FEVI $<50 \%$ normal). Walking was observed (untimed) and scored as follows: normal gait $=0$; walks unassisted, but with evidence of spasticity and/or lower motor neuron involvement $=1$; uses a cane or needs braces $=2$; uses a chair or scooter $=3$; bedridden $=4$. In addition each patient was assigned a one time only score based upon age of onset of symptoms: $<40$ years $=0 ; 40-49$ years $=1$; $50-59$ years $=2 ; 60-69$ years $=3 ; \geq 70$ years $=4$. At each visit the degree of disability for daily living was also scored as follows: copes on own $=1$; needs minimal assistance $=2$; needs daily assistance $=3$, needs continual care $=4$.

\section{Transcranial Magnetic Stimulation Studies}

In addition to routine electrophysiological studies each patient underwent motor evoked potentials (MEPs) elicited by transcranial magnetic stimulation using a Dantec circular coil, with an outer diameter of $10.5 \mathrm{~cm}$ and a $6.5 \mathrm{~cm}$ central hole. The patient was seated comfortably in a temperature maintained environment $\left(20-22^{\circ} \mathrm{C}\right)$. Electromyographic responses were recorded from the thenar or hypothenar muscles employing surface electrodes filled with electrogel. The $G_{1}$ electrode was placed over the muscle belly endplate and the $G_{2}$ electrode over the distal tendinous insertion. ${ }^{12}$

MEPs were elicited with the muscle at rest with the coil placed over the vertex. Audio feedback was used to ensure lack of voluntary muscle activity during cortical stimulation. Relaxation was defined as the absence of EMG activity at a display gain of $20 \mu \mathrm{V} /$ division. In the event that the target muscle was fasciculating, care was taken to deliver the cortical stimulus in a fasciculation-free period. Ten to twenty responses were obtained and the one with the shortest onset latency and largest peak to peak amplitude was measured. The output of the stimulator was $10 \%-15 \%$ above threshold.

Threshold is a measure of excitation of the corticomotoneuron and is defined as the strength or output of the stimulator, expressed as a percentage, required to elicit a potential of $>20$ $\mu \mathrm{V}$ amplitude in 3 out of 5 consecutive trials with the coil in the optimal position. ${ }^{13.15}$ The MEP/CMAP ratio was measured by dividing the maximum amplitude compound muscle action potential (CMAP) elicited by supramaximal electrical stimulation of the median or ulnar nerves at the wrist into the largest cortically evoked response. Central motor delay (CCT) was derived from the latency difference of the MEPs elicited by placing the coil over the cortex and the lower cervical spine in the midline. ${ }^{16}$

Potentials were considered abnormal if any of the following pertained: absent response, latency $>25.0 \mathrm{msec}$, CCT $>11.5$ msec, MEP amplitude $<1.2 \mathrm{mV}$, MEP/CMAP ratio $<10 \%$, threshold $>67.5 \%$. A CMAP of $<6.9 \mathrm{mV}$ was also considered abnormal. Results of baseline cortical stimulation studies in the total cohort at entry have been reported in detail elsewhere. ${ }^{17}$

\section{Statistical Analysis}

The study was monitored continuously by sequential statistical analysis. A double triangular sequential log-rank test was used to follow the survival experience of both groups. ${ }^{18}$ This technique permitted reaching a statistical decision concerning the efficacy or otherwise of lamotrigine in delaying the endpoint (death) as soon as sufficient data had been collected. The test was run at a 2 -sided significance level of $5 \%$, with $80 \%$ power (Figure 1).

In addition, upon termination of the trial, group means were compared by t-tests; counts were compared between groups using chi-square tests.

\section{RESULTS}

\section{Clinical}

The trial was stopped at the end of 18 months. At that time there was sufficient sequential statistical evidence for no difference in survival between lamotrigine and the placebo (Figure 1). The Kaplan-Meier curves for the two groups showed no statistical difference $(p=0.69)$ (Figure 2). Table 1 gives the data for the 67 patients ( 35 men and 32 women) who met the criteria for trial entry. Fifteen patients withdrew in the course of the study and 12 died, leaving 40 at its termination. There was a significant difference between the sex ratios in the two groups, with a lower male : female ratio in the active group $(p<0.01)$. There 


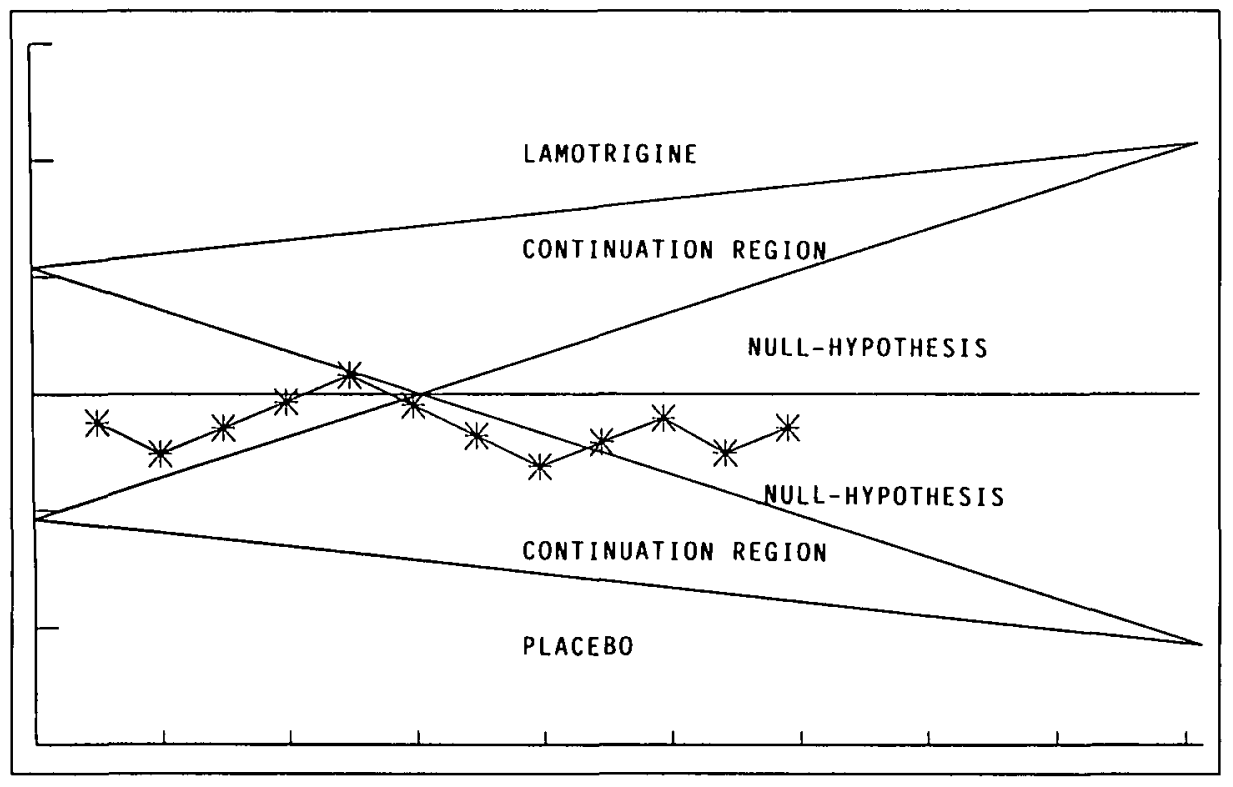

Figure I - Random path described by the sequential statistical analysis. Each poimt on the path corresponds to an end. point. the last being at just over 15 months. The horizontal axis represents time. Had the path crossed into the lamotrigine region it would have indicated statistically that lamotrigine had had a significant effect. Crossing into the mill. hypothesis region indicates sufficient statistical evidence for no difference between lamotrigine and placebo. The curve was run at a 2 -sided significance level of $5 \%$ with a power of $80 \%$.

Table 1. Lamotrigine Versus Placebo Characteristics in 67 Patients With ALS at Trial Entry

\begin{tabular}{|c|c|c|c|}
\hline Data & $\begin{array}{l}\text { Lamotrigine } \\
\quad(n=34)\end{array}$ & $\begin{array}{l}\text { Placebo } \\
(\mathrm{n}=33)\end{array}$ & Significance \\
\hline Age at Entry (yrs) & $57.5 \pm 13.0$ & $58.6 \pm 10.7$ & NS \\
\hline M :F Ratio & $0.62: 1$ & $1.83: 1$ & $p<0.01$ \\
\hline Withdrawn & 9 & 6 & NS \\
\hline Died & 6 & 6 & NS \\
\hline $\begin{array}{l}\text { Disease Duration } \\
\text { at Entry (months) }\end{array}$ & $11.7 \pm 5.3$ & $11.7 \pm 5.4$ & NS \\
\hline Change in Clinical Score & $7.1+3.3$ & $9.0+3.3$ & NS \\
\hline
\end{tabular}

(Values expressed as mean \pm one standard deviation. Disease duration was estimated from the onset of initial symptoms. The male : female ratio for the placebo versus treatment groups is significantly different $\mathrm{p}<0.01$ ).

were no other statistically significant differences between the groups. We analyzed male/female age differences and disease durations within and between groups and they were not statistically different. At trial termination there was no significant difference between the groups with regard to change in their clinical scores (Table1). At trial entry the clinical scores for the active and placebo groups were $5.5 \pm 2.2$ and $4.7 \pm 2.0$ respectively and $12.6 \pm 4.5$ and $13.7 \pm 4.7$ respectively at its termination. The change in clinical score was $7.1 \pm 3.3(n=18)$ and 9.0 $\pm 3.3(n=21)$ for the active versus placebo groups respectively. The difference was not significant $(0.05<p<0.10)$. Changes were not significantly different between men and women within and between the groups.

\section{Side Effects}

One patient developed liver dysfunction after being on active therapy for 10 months and withdrew from the trial. It could not be proven this was drug-induced but his liver function tests became normal within a month of stopping lamotrigine. Two other patients developed a temporary erythematous rash mainly over the upper body. Both were on lamotrigine and the rash settled without having to stop the medication. Other side effects in

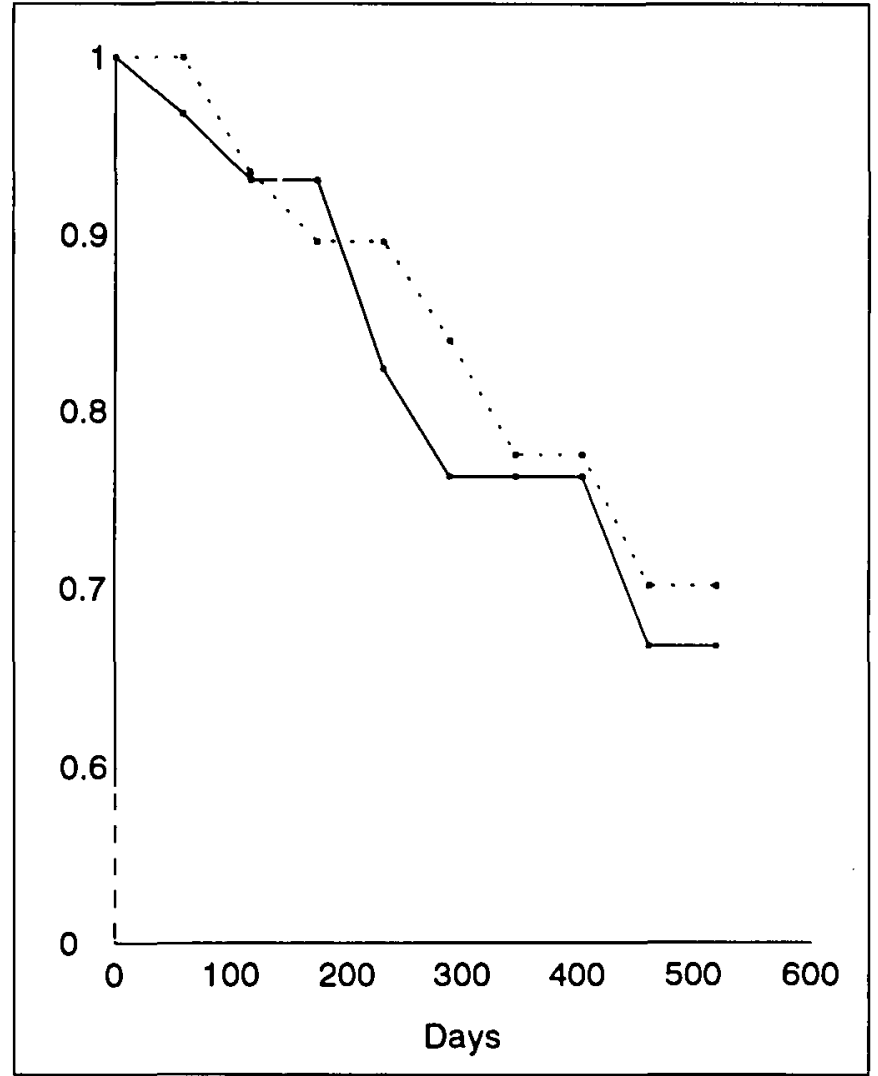

Figure $2-$ Kaplan-Meier curves (interrupted line $=$ placebo) plotted up to the time of termination of the study $(p=0.69)$.

the active treatment group that induced elective withdrawal from the trial included "patient observed" worsening of symptoms ( 3 patients), headache ( 1 patient) and nightmares ( 2 patients). Six patients in the placebo group withdrew because of "a lack of any noticeable improvement" in their disease or because they found it too tedious to comply with the need for return visits. 


\section{Fasciculation}

About a third of the patients on active treatment who had marked clinical fasciculation at entry noticed a dramatic lessening or cessation of this feature after being on lamotrigine for periods of 1-2 weeks. Fasciculation was not measured quantitatively, clinically or electrically so that a statistical comparison with the placebo group, none of whom volunteered a change in the state of their fasciculation, was not possible.

\section{Cortical Stimulation}

Prolongation of the MEP latency and reduction of the CMAP amplitude over the 12 months was significant for both groups (Table 2). However, there were no significant differences in the changes when analyzed between the two groups (Table 2). Although cortical threshold did not change significantly through the trial period the number of patients in whom it was not possible to elicit a MEP increased by $36 \%$ and $57.4 \%$ for the active and placebo groups respectively (Table 2 ). Chi-square analysis of the differences was not significant $\left(X^{2}=0.087\right.$ at entry and $\mathrm{X}^{2}=0.034$ at termination respectively).

\section{Discussion}

Over the eighteen month study period, lamotrigine failed to show significant benefit in ALS. The unproven, albeit simple, clinical assessment we used, may not have been sufficiently sensitive to detect subtle changes in drug versus placebo groups. Utilizing Tufts Quantitative Neuromuscular Examination (TQNE) or the Norris score may have been more revealing. ${ }^{19}$ However, our chief endpoint was death. This was based upon the results of a recent prospective study, in which we determined age-related disease duration in a large cohort of patients with ALS followed from symptom onset to death. ${ }^{20}$ Carrying on the trial for a longer period was precluded by our sequential statistical findings, the increasing rate of patient drop out and a demand to participate in a newly launched multi-centre human recombinant ciliary nerve growth factor (CNTF) trial.

Our findings do not negate the potential of anti-glutamate therapy in ALS nor should they preclude further studies using lamotrigine. Because of its unknown side effects in ALS, the doses we employed were relatively small; about half that used in the successful treatment of refractory epilepsy. A trial using $200-400 \mathrm{mg}$ daily would therefore be of interest. However, lamotrigine mainly acts to inhibit glutamate release ${ }^{7}$ and subsequent to the beginning of this trial it was shown that in ALS there is a defect in high-affinity glutamate transport leading to its defective clearance and resulting exposure of neurons to abnormally high concentrations of glutamate. ${ }^{21,22}$ If such a mechanism can be confirmed it is likely that lamotrigine is less than ideal as a specific antiglutamate therapy in ALS.
Previous therapeutic efforts in ALS that have been directed specifically to the reduction of glutamate excitotoxicity have used branched-chain aminoacids ${ }^{23.24}$ or dextromethorphan. ${ }^{25}$ Based upon a partial deficiency in glutamate chain amino-acids L-leucine and L-isoleucine have been used to activate GDH rationalizing this would reduce local, toxic, levels of glutamate. Significant benefit in ALS with branched-chain aminoacid therapy has not thus far been demonstrated. ${ }^{23,24}$

Dextromethorphan interacts at the N-methyl-D-aspartate (NMDA) receptor. Based upon its glutamate antagonist effects, dextromethorphan has been used successfully to prevent or reduce ischemic neuronal damage in animal models ${ }^{27}$ and electroshock-induced seizures in mice ${ }^{28}$ but it has not proven of value in the treatment of humans with complex partial seizures ${ }^{29}$ (whereas lamotrigine has ${ }^{7}$ ). It has not been efficacious in symptomatic Huntington's Disease. ${ }^{30}$ A single pilot study using dextromethorphan in ALS has proven safe but possible efficacy remains to be reported. ${ }^{25}$

It is possible that failure of the different approaches to antiglutamate therapy that have thus far been tried in ALS is because none of them tackle the prime mechanism of glutamate increase; a defect in high-affinity glutamate transport. ${ }^{21}$ It is also possible that whereas antiglutamate therapy might be rational early in the disease, it could be counter-productive as it progresses when there may in fact be a need to replace glutamate. Changes in glutamate levels in ALS serum and cerebrospinal fluid have shown controversial results ranging from higher to lower than normal. ${ }^{21,22,26,31-34}$ Values have not correlated with severity of disease but relation to disease duration has not generally been considered. The contrasting results of different studies have usually been ascribed to methodological variations. They might equally reflect changing (decreasing) glutamate levels as the disease process progresses.

The decrease in fasciculation noted by a number of patients who were on lamotrigine was of interest. Based upon transcranial magnetic stimulation studies in ALS it has been proposed that fasciculations in this disease arise at least as proximal as the anterior horn cell and possibly even the corticomotoneuron. ${ }^{35}$ This needs substantiation but may reflect glutamate excitotoxicity. It would be of interest to administer a single large dose (400$800 \mathrm{mg}$ ) of lamotrigine and monitor its effect on fasciculations. A single large dose has been given without ill effect to several patients with Parkinson's disease to test any symptomatic effect of the drug in this disease. (Calne and Lee; personal communication).

Over the last decade there has been a variety of diverse therapeutic strategies tried in ALS. None have shown lasting benefit. As our understanding of the etio-pathogenesis of ALS unfolds it is becoming clearer that it is multifactorial. It may therefore be naive to hope for a single effective therapeutic agent and it may

Table 2. Electrophysiological Data in 39 Patients at Entry and After 18 Months of Treatment

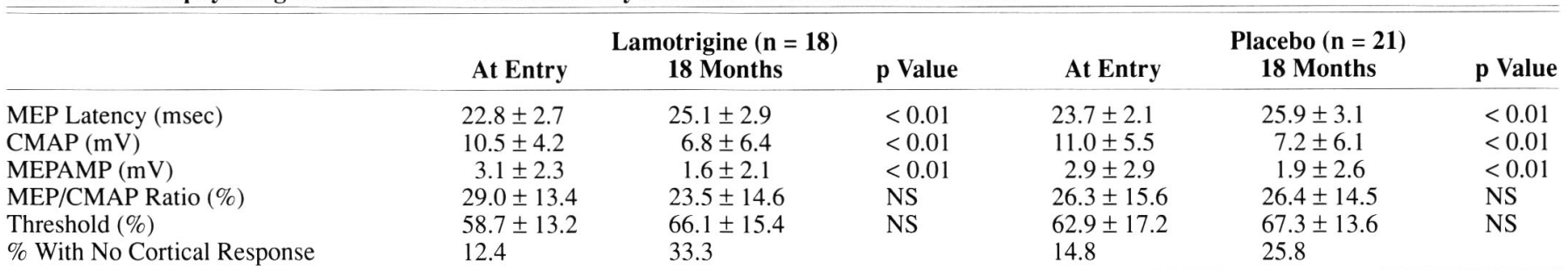


be more logical to treat ALS with multi-therapy tackling a variety of mechanisms that seem to be relevant. At the present time these may include a combination of a glutamate inhibitor, an antioxidant (such as deprenyl or vitamin $\mathrm{E}$ ) and a growth factor. Recent studies have shown genetic defects in both detoxication of superoxide dismutase with the potential for oxidative stress and free radical accumulation ${ }^{36}$ and a defect in the glutamate subunit GluR5 which is located on human chromosome $2 \mathrm{lq}$ in the vicinity of SOD 1 , the gene for familial ALS. ${ }^{37}$

\section{ACKNOWLEDGEMENTS}

We thank the Neurologists of British Columbia for their continuing support in allowing us to help in the management of their patients with ALS. Supported by a grant from the Medical Research Council of Canada (PG-11127) and The ALS Society of British Columbia.

\section{REFERENCES}

1. Choi DW. Glutamate neurotoxicity and diseases of the nervous system. Neuron 1988; 1: 623-634.

2. Plaitakis A. Glutamate dysfunction and selective motor neuron degeneration in amyotrophic lateral sclerosis: a hypothesis. Ann Neurol 1990; 28: 3-8.

3. Young AB. What's the excitement about excitatory amino acids in amyotrophic lateral sclerosis? Ann Neurol 1990; 28: 9-11.

4. Rothstein JD, Tsai G, Kuncl RW, et al. Abnormal excitatory amino acid metabolism in amyotrophic lateral sclerosis. Ann Neurol 1990; 28: 18-25.

5. Weiss JH, Choi DW. Differential vulnerability to excitatory amino acid-induced toxicity and selective neuronal loss in neurodegenerative diseases. Can J Neurol Sci 1991; (Suppl 3): 18: 394-397.

6. Rothstein JD, Kuncl RW, Chaudhry V, et al. Excitatory amino acids in amyotrophic lateral sclerosis: an update. Ann Neurol 1991; 30: 224-225.

7. Brodie MJ. Drug profiles: lamotrigine. Lancet 1992; 339: 1397-1400.

8. Rowland LP. Ten central themes in a decade of ALS research. In: Rowland LP, ed. Advances in Neurology, Vol 56: Amyotrophic Lateral Sclerosis and Other Motor Neuron Diseases. Raven Press Lid., 1991: 3-23.

9. Parry GJ, Clark S. Multifocal acquired demyelinating neuropathy masquerading as motor neuron disease. Muscle Nerve 1988; 11 : 103-107.

10. Pestronk A. Invited review: motor neuronopathies, motor neuron disorders, and antiglycolipid antibodies. Muscle Nerve 1991; 14: 927-936.

11. Daube JR. Electrophysiological studies in the diagnosis and prognosis of motor neuron diseases. Neurol Clin 1985; 3: 473-493.

12. Eisen A. Transcranial magnetic stimulation in amyotrophic lateral sclerosis and some other disorders involving the pyramidal pathways. In: Lissens MA, ed. Clinical Applications of Magnetic Transcranial Stimulation. Leuven: Peeters Press, 1992; 91-105.

13. Hufnagel A, Elger CE, Marx W, Ising A. Magnetic stimulation motor-evoked potentials in epilepsy: effects of the disease and anticonvulsant medications. Ann Neurol 1990; 28: 680-686.

14. Caramia MD, Cicinelli P, Paradiso C, Marioenzi R, et al. Excitability changes of muscular responses to magnetic brain stimulation in patients with central motor disorders. Electroencephalogr Clin Neurophysiol 1991; 81: 243-250.

15. Wassermann EM, McSahane LM, Hallett M, Cohen LG. Noninvasive mapping of muscle representations in human motor cortex. Electroencephalogr Clin Neurophysiol 1992; 85: 1-8.
16. Eisen A, Shtybel W. Clinical experience with transcranial magnetic stimulation. Muscle Nerve 1990; 13: 995-1011.

17. Eisen A, Pant B, Stewart H. Cortical excitability in amyotrophic lateral sclerosis: a clue to pathogenesis. Can J Neurol Sci 1993; 20: $11-16$.

18. Whitehead J. The Design and Analysis of Sequential Clinical Trials. Second Edition. New York: Ellis Horwood, 1992; 74-136.

19. Brooks BR, Sufit RL, DePaul R, et al. Design of clinical therapeutic trials in amyotrophic lateral sclerosis. In: Rowland LP, ed. Advances in Neurology, Vol 56: Amyotrophic Lateral Sclerosis and Other Motor Neuron Diseases. Raven Press Ltd, 1991; 521-546.

20. Eisen A, Schulzer M, MacNeil M, Pant B, et al. Duration of amyotrophic lateral sclerosis is age dependent. Muscle \& Nerve 1993; 16: 27-32.

21. Rothstein JD, Martin LJ, Kuncl RW. Decreased glutamate transport by the brain and spinal cord in amyotrophic lateral sclerosis. $\mathrm{N}$ Engl J Med 1992; 326: 1464-1468.

22. Choi DW. Amyotrophic lateral sclerosis and glutamate - too much of a good thing? N Engl J Med 1992; 326: 1493-1494.

23. Plaitakis A, Smith J, Mandeli J, Yahr MD. Pilot trial of branchedchain aminoacids in amyotrophic lateral sclerosis. Lancet 1988 1: $1015-1018$

24. Testa D, Caraceni T, Fetoni V. Branched-chain amino acids in the treatment of amyotrophic lateral sclerosis. J Neurol 1989; 236: 445-447.

25. Applebaum JS, Salazar-Grueso F, Richman JG, et al. Dextromethorphan in the treatment of ALS: a pilot study. Neurology 1991; 41(Suppl 1): 393p.

26. Plaitakis A, Constantakakis E, Smith J. The neuroexcitotoxic amino acids glutamate and aspartate are altered in the spinal cord and brain in amyotrophic lateral sclerosis. Ann Neurol 1988; 24 446-449.

27. Steinberg GK. Effects of dextromethorphan on regional cerebral blood flow in focal cerebral ischemia. J Cereb Blood Flow Metab 1991; 11: 803-809.

28. Leander JD. Evaluation of dextromethorphan and carbetapentane as anticonvulsants and $\mathrm{N}$-methyl-D-aspartic acid antagonists in mice. Epilepsy Res 1989; 4: 28-33.

29. Fisher RS, Cysyk BJ, Lesser RP, et al. Dextromethorphan for treatment of complex partial seizures. Neurology 1990; 40: 547-549.

30. Walker FO, Hunt VP. An open label trial of dextromethorphan in Huntingtons's disease. J Clin Neuropharmacol 1989; 12: 322-330.

31. Meier DH, Schott KJ. Free amino acid pattern of cerebrospinal fluid in amyotrophic lateral sclerosis. Acta Neurol Scand 1988; 77 50-53.

32. Cottell E, Hutchinson M, Simon J, Harrington MG. Plasma glutamate levels in normal subjects and in patients with amyotrophic lateral sclerosis. Biochem Soc Trans 1990; 18: 283p.

33. Perry TL, Krieger C, Hansen S, Eisen A. Amyotrophic lateral sclerosis: amino acid levels in plasma and cerebrospinal fluid. Ann Neurol 1990; 28: 12-17.

34. Iwasaki Y, Ikeda K, Kinoshita M. Plasma amino acid levels in patients with amyotrophic lateral sclerosis. J Neurol Sci 1992; 107: 219-222.

35. Pant B, Eisen A, Stewart H. Some fasciculations in ALS result from corticomotoneuronal drive. Neurology 1992; 42 (Suppl 3): 468p.

36. Rosen D, Siddique T, Patterson D, Figlewicz DA, et al. Mutations in $\mathrm{Cu} / \mathrm{Zn}$ superoxide dismutase gene are associated with familial amyotrophic lateral sclerosis. Nature 1993; 362: 59-62.

37. Eubanks JH, Puranam RS, Kleckner NW, Bettler B, et al. The gene encoding the glutamate receptor subunit GluR5 is located on human chromosome 2lq21.1-22.1 in the vicinity of the gene for familial amyotrophic lateral sclerosis. Proc Natl Acad Sci USA 1993; 90: 178-182. 